\title{
Reducing Stress and Enhancing the General Well-Being of Teachers Using T’ai Chi Chih ${ }^{\circledR}$ Movements: A Pilot Study
}

\author{
Richard A. Detert, Courtney Derosia, Tracy Caravella, R. Daniel Duquette \\ University of Wisconsin-La Crosse
}

\begin{abstract}
The purpose of this study was to examine the effects of T'ai Chi Chih ${ }^{\circledR}$ (TCC) discipline on the physical symptoms of stress and the general well-being of 35 teachers. Teachers completed 15 hours of instruction and practice in a two-day format with four additional weeks of practice. The 23 teachers who completed pre-posttests showed significant improvement of their general well-being and reduction in perceived stress symptoms. Qualitative data from the teachers supported these results. Within the limitations of the study design it was concluded that this relatively new, easy to learn method of T'ai Chi has potential to enhance well-being and reduce stress symptoms of teachers. Teachers and other educational professionals may want to learn more about T'ai Chi Chih ${ }^{\circledR}$ discipline for its stress reducing benefits and enhancement of general well-being.
\end{abstract}

(c) 2006 Californian Journal of Health Promotion. All rights reserved.

Keywords: T'ai Chi Chih discipline, teacher stress, general well-being, behavior intervention

\section{Introduction}

Late in the nineteenth century, physiologist Claude Bernard taught that one of the most characteristic features of all living beings is their ability to maintain the constancy of their internal milieu, regardless of changes in the surrounding environment. In 1932, Walter B. Cannon called this self-regulating power to maintain constancy, homeostasis. This concept led Hans Selye, world pioneer in the concept of stress, to note that disease was not just suffering, but a fight to maintain the homeostatic balance. From Selye's observations, concepts, and research efforts, the literature on stress, its definitions, causes, and role in health and disease exploded.

The past 40 years has seen many definitions and models of stress evolve (Benson, 1975; Curtis and Detert, 1981; Curtis, Detert, Shindler, \& Zirkel, 1989; Jencks, 1977; Lazarus, 1966; McGrath, 1970; Morgan, 1965; Sears, 1978; Selye, 1976). Early models of stress included the concepts of burnout, events that exceed coping abilities and pressures and demands that create wear and tear on the human body. Collectively, these models portray stress to include the elements of perception, the mobilization of bodily resources in response to a stimulus whether the stimulus is pleasant/desirable or unpleasant/undesirable, and the need for cognitive and behavioral intervention and prevention strategies to assist in neutralizing too much stress.

Early on Selye commented on the importance of perception in eliciting the stress response. He noted that it is not the event that triggers the stress response but how an individual perceives it. How one perceives the source of stress is unique to each individual and is based on complex interactions between their personality, values, coping skills and life circumstances (Kyriacou, 2001; Selye, 1976). When a stimulus (stressor) is perceived by an individual to be a threat, or where one fails to intervene when stress is unrelenting - exhausting one's ability to cope, it becomes one of many factors leading to ill health or disease states. In speaking about coping, Meichenbaum (1985) suggested that the levels of intensity of the stress response is due to a mismatch between the demands made on an individual and their ability to effectively cope with them. In fact, continuous elicitation of the stress response over time has been reported to be 
a major factor in the development of accidents, illness, depression, as well as other societal costs (Benson \& Fryer, 2005; Van Der Linde, 2000).

\section{Teacher Stress}

Teacher stress was first identified as a work issue in the 1930s (Hicks, 1933) and continues to be identified as a problem for many teachers today. A recent survey by Optum Research, a Minnesota-based company that studies workrelated health risks, found that 88 percent of teachers experience moderate to high levels of stress (Crute, 2001). Kayiocaus (2001) described teacher stress as "the experience by a teacher of unpleasant, negative emotions, such as anger, anxiety, tension, frustration or depression, resulting from some aspect of their work as a teacher" (p. 2). Using this definition, it is easy to see that today's teachers experience a great deal of work stress. Further, Reese (2004) noted that (a) work-related stress results from the combination of high job demands and low control over how the job is done and (b) when teachers perceive that their work is highly demanding but that they have little decisionmaking ability. Various teacher literature and research has identified many sources of teacher stress (Baker, 1999; Bernard, 1989; Black, 2000; Blasé, Dedrick \& Strathe, 1986; Boyle et al., 1995; Chen \& Miller, 1997; Farber, 1991; Forman, 1990; Forlin, 2001; Hansen \& Sullivan, 2003; Harris, Halprin \& Halprin, 1985; Kohn, 2000; Kyriacou, 2001; Littrell \& Billingsley, 1994; Nagel \& Brown, 2003; Pahnos, 1990; Pelsma, 2000; Reese, 2004; Rosenholtz, 1989; Turk, Meeks, \& Turk, 1992). These sources of teacher stress are listed in Table 1.

Table 1

Sources of Teacher Stress*

- teaching students who lack motivation

- spending in corrective discipline

- increasing time pressures and workload

- coping with continual change, often leading to conflicting priorities

- being evaluated by others - colleagues, administrators, legislators, parents

- having poor relationships with colleagues and administrators

- having poor working conditions in school

- teaching larger class sizes

- conflicting demands and expectations

- feeling dissatisfied in teaching role

- experiencing a lack of social support from colleagues, friends, family

- increasing the use of high stakes testing and student assessment

- increasing role ambiguity; i.e., confusing information regarding expectations or unclear information about how to meet them

- decreasing budgets leading to no or small salary increments

* Note: Presented here are commonly reported stressors of teachers. This list does not include the myriad of personal stressors that teachers may experience outside the school worksite.

\section{General Stress Management Approaches}

If stress and disease models represent a valid interpretation of the theoretical sequence of events, then controlling stress is based upon developing and implementing strategies to interrupt the sequence of events that trigger the stress response. Reducing stress can be accomplished through programs that mediate the wear and tear from too much stress. One outcome of a study by Detert and Russell (1987) described a stress management program to be any combination of education, skills, and 
rehearsal of coping skills aimed at reducing the frequency and/or the intensity of the stress response to prevent or reduce harmful outcomes. The goal of managing stress is not the total elimination of stress but one of directing and channeling the stress response so it promotes personal challenge, productivity, growth experiences, and improvement of the over all quality of life.

Stress management programs are also based on the premise that stressors are not always amenable to change, but an individual's reaction to and perception of them can be changed. Inherent in this premise is that there is no single stress management technique that will work for every person, or for the same person in different stressful situations. Today's most popular stressreducing technique may not be the most effective or the most useful for a particular person. Each technique serves a specific purpose, but if it is done at the exclusion of other techniques, or without consideration of the complexities of the whole person and transactions within their social and physical environments, stress management efforts may not be effective. Because there is no single process that works equally well for everyone, individuals must find the techniques that work best for them. Specific stress reduction programs for teachers have shown to be effective when they are comprehensive; i.e., active, passive, behavioral, structural, and perceptual (Lang, 1985; Pahnos, 1990; Yoon, 2000).

\section{T'ai Chi as Stress Management}

Alternative approaches for health and healing have become popular in the last decade. For example, the practices of yoga, massage therapy, aromatherapy, and T'ai Chi have grown quickly in recent years (Armoudian, 1995; Horstman, 2000). Specifically, opportunities to learn T’ai Chi as a relaxation and moving meditation practice in the United States for personal health promotion and wellness have increased (Lumsden, Baccals, \& Martiare, 1998), as has the research demonstrating the effectiveness of this ancient Chinese practice.

As Chen and Snyder (1999) noted there are several different forms of T'ai Chi. Collectively these forms involve "a series of fluid, continuous, graceful, dance-like postures” where "graceful body movements are integrated by mind concentration, balance shifting of the body weight, muscle relaxation, and breathing control” (p. 268). Traditional forms of T'ai Chi Ch'uan report the physical benefits of relaxation (Brown, Wang, Ward, Ebbeling, Fortlage, Puleo, Benson, \& Rippe, 1995; Jin, 1989; Koh, 1981); reduced tension (Brown et al., 1995; Jin, 1989; Lehman \& Fees, 1998); reduced fatigue (Jin, 1989; Lehman \& Fees, 1998); decreased anger (Jin, 1989; Lehman \& Fees, 1998); improved depression (Brown et al., 1995; Lehman \& Fees, 1998); and decreased state anxiety (Jin, 1989, 1992; Lehman \& Fees, 1998). Reported psychological and mental benefits of T'ai Chi include increased positive mood states (Brown, et al., 1994; Jin, 1989); increased control of mental and emotional processes (Sun, Dosch, Gilmore, Pemberton, \& Scarseth (1996); and increased calmness and patience (Delza, 1992).

In their 1999 report, Chen and Snyder noted that there is a western from of T'ai Chi called T'ai Chi Chih. Justin Stone developed T'ai Chi Chih discipline, a newer and simpler form of T'ai Chi in the 1970s. T'ai Chi Chih discipline is a gigong-based practice of 19 soft and gentle movements with one closing posture that has the major principles of T'ai Chi disciplines embodied within it. The movements are performed in a continuous flow of circles, ovals, and arcs, repeating movements in repetitions of 9. They are performed at a slow, steady speed as if one was moving in water or heavy air. Rigidity is eliminated in favor of softness and an evenness of movement - an "effort of no effort". The mind becomes focused and alert, paying attention to the preciseness and full expression of each movement. These movements can be learned at any age and require no special attire or equipment (Stone, 1996, 1994). There is a seated version for those who have physical limitations.

Unlike the studies on the benefits of T'ai Chi Ch'uan in reducing aspects of stress, only one empirical study was found describing the effects of T'ai Chi Chih for managing an aspect of stress. Shaller (1996) examined the effects of 
T’ai Chi Chih discipline on balance, flexibility, mood, health status, and blood pressure of healthy community-dwelling elders. Results of this study showed that T'ai Chi Chih discipline improved only balance in this sample. Mood, as measured by the Profile of Mood States (POMS) inventory, showed no difference between the experimental and control group on the presence and intensity of tension-anxiety, depressiondejection, anger, hostility, vigor-activity, fatigue-inertia, or confusion-bewilderment. Thus, it is reasonably safe to say that empirical studies on the effect of T'ai Chi Chih as a viable form of stress reduction in general, and teacher stress in specific, or the enhancement of general well-being are non-existent.

The vast majority of reported benefits, then, from T'ai Chi Chih discipline have come from a plethora of anecdotal evidence about its ability to produce a sense of calmness and relaxation in the body. Therefore, the purpose of this pilot study was to examine whether teachers who learned and practiced T'ai Chi Chih discipline would report changes in self-reported physical symptoms of stress and general well-being.

\section{Methods and Procedures \\ Subjects}

The sample consisted of 35 teachers, 34 Caucasian females and one African American male. The ages ranged from 25 to 32 . Four of the 35 teachers had heard of T'ai Chi Chih discipline and experienced three to four movements as part of a prior graduate philosophy class. One additional teacher had had previous experience with T'ai Chi Ch'uan, yang short form. All teachers were professionals working in educational settings who took T'ai Chi Chih instruction as part of their continuing education.

\section{Instrumentation}

The researchers used four instruments for this study. The instruments included a demographic information questionnaire, the General wellbeing Schedule (GWB), the Taylor Manifest anxiety Scale (TMAS), and a practice log.

Demographic Information Questionnaire. The demographic questionnaire was developed by the researchers. The questionnaire included name, address, telephone number, age, ethnic background, gender, educational status, and previous experience with T'ai Chi Chih discipline or other mindfulness strategies.

General Well-being Schedule (GWB). The GWB is an 18 item self-administered questionnaire of subjective well-being and distress. Response options provide indications of the presence, severity, and frequency of symptoms of subjective well-being and distress; i.e., how individuals feel about their "inner personal state" during the last month. The GWB has six sub scales that rate (a) anxiety, (b) depression, (c) positive well-being, (d) selfcontrol, (e) vitality, and (f) general health. Sub scale values can be summed to create a total score. Total GWB scores range from 0 to 110 . Based on a national sample, the total GWB score fall into one of three categories. A score of 0-60 is the Clinically Significant Distress category; a score of 61-72 is in the Problemic-Indicative Stress category or moderate distress, and a score of 73-110 is in the Positive Well-being category. These three categories are further broken down in subcategories. The GWB has a test-retest reliability of between 0.69 and 0.85 for the total GWB scale with a three-month timeframe between testing periods. The internal coefficients for the total GWB ranged from 0.94 to 0.91 for females and males respectively. Reliability and validity tests show extremely good results with the internal consistency higher than other scales, specifically depression and anxiety scales (McDowell \& Newell, 1987; Public Health Service, 1977).

Taylor Manifest Anxiety Scale (TMAS). The TMAS is a 50-point subjective interpretation of how many stress manifestations (physical or mental) one experiences relative to other people. The range of scores is $0-50$, with a mean score of 19. A score of 19 indicates a perception of oneself experiencing no more or less stress manifestations than the average person. A score less than 19 indicates one perceives oneself less anxious/stressed than the average person, and a score more than 19 indicates a perception of greater anxiety/stress than the average person. Twenty percent of the population scores greater 
than 19 while $20 \%$ of the population scores less than seven. Although mean scores for women were higher, there was no statistically significant difference between men and women, therefore gender is included as a single distribution.

Test-retest with three different groups spanning three weeks, five months, and 17 months yielded Pearson product-moment coefficients of .89, .82, and .81 respectively. In all cases the mean of each of the three sets of scores remained essentially the same after retesting (Taylor, 1953).

Practice Log. The practice log was developed by the researchers. The log included space to record T'ai Chi Chih movements practiced, date of practice, amount of time in minutes spent in practice. Teachers also recorded any other mindfulness strategies they practiced using the same format. Teachers recorded in their practice logs for 4 weeks following the 15 hour instruction period. At the end of the four weeks of practice, teachers were asked to synthesize their log by writing a summary of perceived benefits from their T'ai Chi Chih practice. The summaries and logs were returned to the researchers following the completion of the 4 weeks of practice.

\section{Treatment}

The treatment for this pilot study consisted of 15 hours of T'ai Chi Chih instruction and practice along with other mindfulness strategies, taught by an accredited T'ai Chi Chih instructor. Subjects were taught and practiced 15 of 19 movements and the one closing posture. T'ai Chi Chih movements accounted for 12 of the 15 hours of instruction and practice. Four movements were omitted due to time constraints of the two-day format. To complement T'ai Chi Chih practice and to provide periods of rest, the teachers were also taught; (a) mindful breathing, b) mindful sensory awareness, (c) mindful thinking, (d) mindful eating, and (e) mindful walking during the other three hours (Braza, 1997). These strategies were chosen because they reinforce key aspects that are embodied in T'ai Chi Chih discipline. Teachers were asked to practice T'ai Chi Chih for four weeks following the initial instruction. All teachers had access to a T'ai Chi Chih teaching book (Stone, 1996). The telephone number and email address of the accredited instructor were provided in the event teachers had questions about any of the T'ai Chi Chih movements.

\section{Measure Procedures}

During the first half-hour of the initial meeting, the purpose of the study was explained to the teachers and they were asked to complete an informed consent form, the demographic information questionnaire, the GWB, and the TMAS. Teachers were informed that by providing their name and address they would be giving permission to complete the assessment package again at a future date. A package with the GWB, the TMAS, a stamped return envelope, and a cover letter with a brief set of instructions was mailed to each teacher four weeks after the program. They were instructed to complete and return the assessments within seven working days. An established protocol was followed during all data collection times.

\section{Data Analysis}

Data were analyzed using a t-test for each of the total GWB scores, each of the GWB subscale scores, and the TMAS scores. We coded the qualitative data from the teachers' personal summaries as suggested by Coffey and Atkinson (1996). Words and ideas that appeared most often in the coding were examined for themes about the subject's perceived benefits of T'ai Chi Chih practice. Sample quotes were used to support each theme and set of words or ideas.

\section{Results}

\section{Quantitative}

Of the 35 teachers who completed the pretest and T'ai Chi Chih instruction, 23 completed and returned the posttest; a response rate of $65.7 \%$. T-test analysis between the pre-and posttest mean scores of the total GWB, the six GWB subscales, and the TMAS showed statistically significant results. All t-tests were significant at the .05 or lower probability level. Total GWB mean scores increased from 65.56 to 80.04 at posttest, significant at the .0001 level. This indicates that, as a group, there was significant change in their reported general well-being. Each of the six subscales showed similar results. 
The General Health subscale showed a change from a mean score of 9.74 at pretest to a mean score of 11.19 at posttest, significant at the .05 level. The Vitality subscale showed a change from a mean score of 10.00 at pretest to a mean score of 13.07 at posttest, significant at the .05 level. The Positive Well-being subscale showed a change from a mean score of 5.96 at pretest to a mean score of 6.89 at posttest, significant at the .001 level. The Depression subscale showed a change from a mean score of 16.19 at pretest to a mean score of 19.04 at posttest, significant at the .001 level. The Anxiety subscale showed a change from a mean score of 13.44 at pretest to a mean score of 17.44 at posttest, significant at the .05 level. The Self Control subscale showed a change from a mean score of 10.41 at pretest to a mean score of 12.41 at posttest, significant at the .001 level.

Similar to the total GWB and the GWB subscales, the TMAS showed statistical significance in a positive direction. The TMAS showed a change from a mean score of 15.89 at pretest to a mean score of 9.67 at posttest. The change was significant at the .001 level.

\section{Qualitative}

The statistical results were reinforced by the qualitative data of 20 teachers' perceived benefits of T'ai Chi Chih practice. Four major themes emerged from the qualitative data. They were: (1) General Physical benefits, (2) Physical Ailment Benefits, (3) Psychological/Mental benefits, and (4) Spiritual Benefits.

Theme 1: General Physical Benefits. Coded responses leading to this theme included increase circulation; increased energy levels; increased relaxation; increased balance, leg strength, body endurance, posture, range of motion, coordination, and flexibility; increased exercise; decreased tension, anxiety, and stress levels; feeling refreshed and rejuvenated; feel good physically; and increased graceful feeling. Sample quotes from teachers that support these benefits included:

"When I practice T’ai Chi [Chih] I experience periods of relief from this tension."

"I have...a sense of grace, energy, and calmness."

"I have experienced an increase in my daily energy levels and endurance."

Table 2

Pre-and posttest differences of the total GWB, the GWB subscales, and Taylor Manifest Anxiety Scale (TMAS) $(\mathrm{N}=23)$

\begin{tabular}{|c|c|c|c|c|c|}
\hline \multirow[b]{2}{*}{ Measure } & \multicolumn{2}{|c|}{ Pretest } & \multicolumn{2}{|c|}{ Posttest } & \multirow[b]{2}{*}{$\mathbf{t}$} \\
\hline & $\mathbf{M}$ & SD & $\mathbf{M}$ & SD & \\
\hline GWB Total & 65.56 & 17.75 & 80.04 & 14.64 & $-4.941 * *$ \\
\hline GWB Subscale 1 & 9.74 & 3.39 & 11.19 & .16 & $-2.067^{*}$ \\
\hline GWB Subscale 2 & 10.00 & 3.97 & 13.07 & 3.30 & $-3.832 *$ \\
\hline GWB Subscale 3 & 5.96 & 2.26 & 6.89 & 2.06 & $-2.560 *$ \\
\hline GWB Subscale 4 & 16.19 & 4.55 & 10.04 & 3.55 & $-4.008 * *$ \\
\hline GWB Subscale 5 & 13.44 & 4.14 & 17.44 & 4.99 & $-4.058 * *$ \\
\hline GWB Subscale 6 & 10.41 & 2.83 & 12.41 & 2.39 & $-4.298 * *$ \\
\hline TMAS & 15.89 & 8.52 & 9.67 & 7.09 & $4.852 * *$ \\
\hline $\begin{aligned} \text { Note: * Significant }<.05 \\
\text { Subscale: } 1=\text { General } \\
2=\text { Vitality } \\
3=\text { Positive } \\
4=\text { Depressic } \\
5=\text { Anxiety } \\
6=\text { Self Cont } \\
\text { TMAS }=\text { Tay }\end{aligned}$ & $\begin{array}{l}\text { Significal } \\
\text { h (freedor } \\
\text { gy) } \\
\text {-being (sa } \\
\text { heerful vs } \\
\text { xed vs. ten } \\
\text { emotional } \\
\text { Manifest A }\end{array}$ & $\begin{array}{l}001 \\
\text { m health } \\
\text { ing and int } \\
\text { ressed) } \\
\text { inxious) } \\
\text { avioral co } \\
\text { ety Scale }\end{array}$ & $\begin{array}{l}\text { cern, worr } \\
\text { sting life) }\end{array}$ & ress) & \\
\hline
\end{tabular}


Theme 2: Psychological/Mental Benefits. Coded responses leading to this theme included decreased stress levels; increased peacefulness, serenity, happiness, joy, satisfaction; increased focus, concentration, and mental clarity. Sample quotes from teachers that support these benefits included:

"It refreshes me and makes it easier to focus on my next task."

"There is always a sense of calmness and joy that increased as the practice time continues."

"I am more open and connected in my personal relationships and feel much less stress in my daily life."

"The quality of my mornings, my attitude for the day beginning, my eating habits, my sleeping ease and much more are all positively changed...and in such a short time."

Theme 3: Physical Ailments Benefits. Coded responses leading to this theme included decreased pain in the body, physical ailments, achiness, leg cramping, and bowel problems; decreased number of headaches; and quicker healing time. Sample quotes from teachers that support these benefits included:

"I noted...having increased energy, less achiness in joints and the beginnings of more flexibility."

"Steps three, ten, and eleven seemed to melt the frozen stiffness of my neck and shoulders....I have less cracking sensations and much more mobility in the rotation of my head. My ankle, heal problem is virtually gone."

"Previous to doing T'ai Chi [Chih], I have often had digestive troubles and one very good benefit I've noticed is that I have not been bothered by constipation.”

Theme 4: Spiritual Awareness. Coded responses leading to this theme included a deepening of spirituality and fulfillment; and increased feeling of connectedness. Sample quotes for this theme include:
"On an internal level, I have begun to experience new and different levels of inner calmness, control, focus, purpose of mind, enhanced concentration, intent alertness, and spiritual depth.”

"This seems to center me and increases my inner peace."

“T'ai Chi Chih has benefited my spirituality and inner peace.”

\section{Discussions and Implications}

The 65.6\% response rate following the four weeks of practice was a little disappointing. We anticipated at least 30 complete response sets to be analyzed. No follow-up was done to determine reasons why teachers didn't return the post assessment instruments. One teacher did mention to us that she did not continue T'ai Chi Chih practice beyond the instruction phase due to religious beliefs. Although personal contacts may have increased the response rate, we believed it was more important to collect data from those who voluntarily continued to practice on their own and who would provide the followup data at the end of the four weeks.

Because the GWB is very reliable in assessing the inner personal state during the previous four weeks, teachers in this study at pretest perceived enough symptoms of distress to be placed in the mild problem-indicative stress category. At posttest, teachers' perceptions changed to reflect a moderately high mood of positive well-being. This is not surprising considering all six subscales showed significant change from preto posttest. At posttest, teachers perceived themselves to be experiencing significantly less distress, worry, and concern for their health, increased vitality (energy), increased in having a satisfying and interesting life, more cheerfulness, more relaxed with less tenseness and anxiety, and greater emotional-behavioral control. The largest changes occurred in subscales four, five, and six which have to do with depression, anxiety, and self control. A major aspect of T'ai Chi Chih discipline is to have the body relaxed during the movements, having relaxed shoulders, arms, wrists, and fingers is a major principle of all the T'ai Chi Chih movements. Further, soft, slow and 
continuous movement creating circles, ovals, and arcs are used not only to activate and balance the intrinsic energy of the body, but to create a strong mental focus. It is this mental concentration that makes T'ai Chi Chih discipline a moving meditation, which may bring about a relaxing feeling within the individual. Although postulated about T'ai Chi Ch'uan and Qigong, Benson (as cited in Eisenberg, 1995) believes that the positive results may be due to the elicitation of the relaxation response. Benefits may also be from the integration of mind and body that allows individuals to gain greater emotional-behavioral control. These results are consistent with the research on T'ai Chi Ch'uan by several researchers. Jin (1989, 1992) and Lehman and Fees (1998) found decreased state anxiety, while Sun et al. (1996) found an increased control of mental and emotional processes.

Responses on the TMAS indicate subjective interpretation of how many stress manifestations one perceives. Similar to the GWB, the teachers' scores on the TMAS moved significantly in a positive direction - their total scores decreased. Scores were close to the low $20 \%$ of the national sample at posttest, which indicates teachers perceived far fewer symptoms associated with stress at posttest than at pretest. This finding is also consistent with previous research with T'ai Chi Ch'uan. Jin (1989) and Lehman and Fees (1998) found decreased fatigue while Brown et al. (1994), Jacobson et al. (1997), and Lehman and Fees (1998) found decreased tension.

The GWB and TMAS results are not only substantiated in previous T'ai Chi Ch'uan literature but also in the qualitative analysis of teachers' comments. The same variables assessed by the GWB and TMAS that changed over the four weeks were expressed by subjects in their summary reviews. Additionally, teachers spoke of healing that had occurred. This healing was noted as reduction in joint pain, headaches, digestive problems, and constipation. It is unknown from this study if the healing is the result of less stress, anxiety, worry, and health concern brought about from the T'ai Chi Chih practice, or if the practice serves as a placebo effect. It may be a synergistic result of both as well as the increased spiritual awareness that occurred for several of the teachers. Regardless, for these teachers the effects were perceived as "real healings" that came about within the four weeks of practice.

Although there was no attempt to objectively qualify perceptions about the spiritual benefits that came with T'ai Chi Chih practice, several teachers did note that their spirituality was benefited in their synthesis. Teachers who spoke directly about the spiritual benefits mentioned that T'ai Chi Chih helped to elicit inner stillness and inner peace. From this perspective, all the benefits mentioned above may be the result of this inner stillness and peace, or the relaxation response, but was not perceived as such by most of the teachers. It is important not to put too much importance on this aspect of the study because spirituality was not defined in any specific manner as a reference point for them. Because spirituality means different things to different people, what is mentioned as "spiritual" for one may not be spiritual for another.

What can be derived from these results is limited, but encouraging. Since this pilot study was a single sample, pre-post test design, it lacked specific controls to be able to generalize the results to a larger population. Results are further compromised because there was no control group where comparisons could be made to establish the T'ai Chi Chih treatment was what made the difference from pre-to posttest results. Future studies that use larger, randomly sampled groups where one of the groups can serve as a control will be helpful in testing out the effects of T'ai Chi Chih practice relative to stress reduction and other health enhancing qualities for teachers. It would be wise to use instruments other than self-report such as measuring blood pressure with a sphygmomanometer and stethoscope, measuring peripheral blood circulation with a photoelectric earlobe sphymograph, using a laser microcirculation blood flow meter to measure blood flow in the fingertips, and measure body temperature and muscle tension with a biofeedback machine. 
On the other hand, qualitative studies where T'ai Chi Chih practitioners are interviewed may reveal a plethora of information about reducing stress that will continue to strengthen the role of T'ai Chi Chih discipline in reducing stress. For thousands of years, self-reports and journals have been the major vehicles used to report and describe the benefits of T'ai Chi practices. Systematic methods of analyzing written or verbal data will add much to the efficacy of T'ai Chi Chih discipline as a mediator of too much stress and anxiety in daily living. The results of such qualitative studies may become the building blocks for theory testing using more rigorous quantitative research methods.

Nonetheless, the results of this pilot study are very encouraging on two fronts. The first is that the results presented here warrant that teachers, administrators, and school board members become more aware of T'ai Chi Chih discipline as an effective vehicle for managing stress and enhancing general well-being, especially with the mounting stress that today's teachers experience. The second is that its simplicity in design and ease of learning make T'ai Chi Chih discipline an excellent intervention for not only ameliorating stress, but in maintaining general well-being for teachers. Stone (1994) noted one limitation of T'ai Chi Ch'uan is the difficulty in learning the movements and the benefits come only when students have mastered the moves, taking between eight months to two years. This strains the commitment of even the most dedicated T'ai Chi student. Considering that T'ai Chi Chih discipline appears to have such a profound change in the areas examined here in just four weeks of practice, it is certainly worth promoting as a personal health practice within the teaching profession. As one T'ai Chi Chih instructor noted, regular T'ai Chi Chih practice helps one to loosen their grip on stress and increase their grasp on life. We hope our initial efforts with this pilot study encourage educational professionals to learn about and work with this discipline for reducing stress and enhancing general well-being.

\section{References}

Armoundian, M. (1995). Keeping mental health in mind: Muscle-flexing gives way to flexibility and relaxation as stress-reducing techniques like yoga and T'ai Chi gain in popularity. Billboard, 107(43), 78-80.

Baker, J. A. (1999). Teacher-student interaction in urban at-risk classrooms: Differential behavior, relationship quality, and student satisfaction with school. Elementary School Journal, 100(1), 5770.

Benson, H. (1975). The relaxation response. NY: Avon Books.

Benson, H. (1997). Timeless healing: The power and biology of belief. NY: Fireside.

Benson, H., \& Fryer, B. (2005). Are you working too hard? [Electronic version]. Harvard Business Review. Retrieved November 8, 2005, from http://harvardbusinessonline.hbsp.harvard.edu/hbrsa/en/issue/0511/article/R0511Bprint

Bernard, M. E. (1989). Teachers stress: Factors contributing to teacher stress: Implications for research, prevention, and remediation. Behavioral Counseling, 2(1), 3-25.

Black, J. J., Dedrick, C., \& Strathe, M. (1986). Leadership behavior of school principals in relation to teacher stress, satisfaction, and performance. Journal of Humanistic Education and Development, 24, 159-171.

Boyle, G. J., Borg, M. G., Falzon, J. M., \& Bagliani, A. J. (1995). A structural model of the dimensions of teacher stress. British Journal of Educational Psychology, 65(1) 49-67.

Braza, G. (1997). Moment by moment: The art and practice of mindfulness. Boston, MA: Tuttle.

Brown, D. R., Wang, Y., Ward, A., Ebbeling, C. A., Fortlage, L., Puleo, E., Benson, H., \& Rippe, J. M. (1995). Chronic psychological effects of exercise and exercise plus cognitive strategies. Medicine and Science in Sports and Exercise, 27, 765-775.

Chen, K-M., \& Snyder, M. (1999). A research-based use of tai chi/movement therapy as a nursing intervention. Journal of Holistic Nursing, 17(3), 267-279. 
Chen, M. R., \& Miller, G. (1987). Teacher stress: A review of the international literature. ERIC Document Reproduction Service No. ED 410187.

Coffey, A., \& Atkinson, P. (1996). Making sense of qualitative data. Thousand Oaks, CA: Sage.

Crute, S. (2004/Jan). Stressed out. [Electronic version]. NEA Today, 22(4). Retrieved March 14, 2005, from Academic Search Premier database.

Curtis, J.D., \& Detert, R.A. (1981). How to relax: A holistic approach to stress management. Palo Alto, CA: Mayfield.

Curtis, J. D., Detert, R. A., Shindler, J., \& Zirkel, K. (1989). Teaching stress management and relaxation skills: An instructor's guide. La Crosse, WI: Coulee Press.

Delza, S. (1992). T’ai Chi Ch’uan. Dance Magazine, 66(3), 56-57.

Detert, R. A., \& Russell, R. (1987). Identification and description of content elements for stress management in health education. Health Values, 11(01), 3-12.

Eisenberg, D. (1995). Encounters with qi: Exploring Chinese medicine. NY: W. Norton.

Farber, B. (1991). Crises in education: Stress and burnout in the American teacher. San Francisco, CA: Jossey-Bass.

Forlin, C. (2001). Includsion: Identifying potential stressors for regular class teachers. Educational Research, 43(3), 235-245.

Forman, S. (1990). Rational-emotive therapy: Contributions to teacher stress management. [Electronic version]. School Psychology Review, 19(3). Retrieved March 14, 2005, from Academic Search Premier database.

Goldstein, M. R. (1977). The use of relaxation and cognitive relabeling as coping skills. In R. B. Stuart (Ed.), Behavioral self-management (pp. 82-116). NY: Bresemer/Mazel.

Hansen, J., \& Sullivan, B. (2003). Chapter 43 Assessment of workplace stress: Occupational stress, its consequences, and common causes of teacher stress. (ERIC Document Reproduction Service No. ED 480 078)

Haris, K., Halprin, G., \& Halprin, G. (1985). Teacher characteristics and stress. Journal of Educational Stress, 78 (6), 346-350.

Horstman, J. (2000). Tai chi. Explorations: Complementary, Alternative and Unproven Treatments, 6062.

Jencks, B. (1977). Your body: Biofeedback at its best. Chicago: Nelson Hall.

Jin, P. (1989). Changes in heart rate, noradrenaline, cortisol and mood during T'ai Chi. Journal of Psychosomatic Research, 32(2), 197-205.

Jin, P. (1992). Efficacy of Tai Chi, brisk walking, meditation, and reading in reducing mental and emotional stress. Journal of Psychosomatic Research, 36 (4), 361-370.

Koh, T. C. (1981). Tai chi chuan. American Journal of Chinese Medicine, 9, 15-22.

Kohn, A. (2000). The case against standardized testing. Portsmouth, NH: Heineman.

Kyriacou, C. (2001). Teacher stress: Directions for future research. [Electronic version]. Educational Review, 0013-1911, 53(1). Retrieved March 5, 2005 from Academic Search Elite database.

Lang, B. (1985). Stress management for school personnel: Stress-innoculation training and exercise. Psychology in the Schools, 25, 314-324.

Lazarus, R. S. (1966). Psychological stress and the coping process. NY: McGraw-Hill.

Lehman, R. A., \& Fees, M. A. (1998). T'ai Chi for balance, part 1. Athletic Therapy Today, 3(5), 17-18.

Littrell, P. C., \& Billingsley, B. S. (1994). The effects of principal support on special and general educators' stress, job satisfaction, school commitment, health, and intent to stay in teaching. [Electronic version]. Remedial \& Special Education, 15(5). Retrieved March 14, 2005, from Academic Search Premier database.

Lumsden, D. B., Baccals, A., \& Martiare, J. (1998). T’ai Chi for osteoarthritis primary care patients. Geriatrics, 53(2), 84-88.

McDowell, I., \& Newell, C. (1987). Measuring health: A guide to rating scales and questionnaires (pp. 125-133). NY: Oxford University Press.

McGrath, J. E. (Ed.). (1970). Social and psychological factors in stress. NY: Holt, Rinehart \& Winston. 
Meichenbaum, D. (1985). Stress inoculation training. NY: Pergamon Press.

Morgan, C. T. (1965). Physiological psychology. NY: McGraw-Hill.

Nagel, L., \& Brown, S. (2003). The ABCs of managing teacher stress. Clearing House, 0009-8655, 76(5). Retrieved March 5, 2005, from Academic Search Elite database.

Pahnos, M. L. (1990). The principal as the primary mediator of school stress. [Electronic version]. Education, 111(1). Retrieved March 14, 2005, from Academic Search Premier database.

Pelsma, D. M. (2000). School counselors' use of solution-focused questioning to improve teacher work life. [Electronic version]. Professional School Counseling, 4(1). Retrieved March 14, 2005, from Academic Search Premier database.

Public Health Service. (1997). A concurrent validational study of the NCHS general well-being schedule. Vital and Health Statistics, 2(73), 1-53.

Reese, R. (2004/August). The bottom line: Strategies for reducing teacher stress — and protecting your investment in new teachers. [Electronic version]. American School Board Journal, 26-27. Retrieved March 14, 2005, from Academic Search Premier database.

Rosch, P. (1991). Is job stress America's leading adult health problem? A commentary. Business Insights, 7(1), 4-7.

Rosenholtz, S. J. (1989). Workplace conditions that affect teacher quality and commitment: Implications for teacher induction programs. The Elementary School Journal, 89, 421-438.

Sears, J. L. (1978). Managing your stress. Journal of Extension, 16, 18-22.

Selye, H. (1974). Stress without distress. NY: Signet.

Selye, H. (1976). The stress of life. NY: McGraw-Hill.

Shaller, K. J. (1996). Tai Chi Chih: An exercise option for older adults. Journal of Gerontological Nursing, 22(10), 12-17.

Stone, J. (1994). Heightened awareness: Toward a higher consciousness. Fort Yates, ND: Good Karma Publishing.

Stone, J. (1996). T’ai Chi Chih: Joy thru movement. Fort Yates, ND: Good Karma Publishing.

Sun W.Y., Dosch, M., Gilmore, G.D., Pemberton, W., \& Scarseth, T. (1996). Effects of a tai chi chuan program on Hmong American older adults. Educational Gerontology, 22(2), 161-167.

Taylor, J. A. (1953). A personality scale of manifest anxiety. The Journal of Abnormal Psychology, 48 (2), 285-290.

Turk, C. C., Meeks, S., \& Turk, L. M. (1982). Factors contributing to teacher stress: Implications for research, prevention, and remediation. Behavioral Counseling Quarterly, 2(1), 3-25.

Van Der Linde, C.H. (2000). The teachers stress and its implications for the school as an organization: How can TQM help? [Electronic version] Education, 00131172, 121(2). Retrieved March 14, 2005, from Academic Search Premier database.

Yoon, J. S. (2000). Teacher characteristics as predictors of teacher-student relationships: Stress, negative affect, and self-efficacy. Social Behavior and Personality, 30(5), 485-494.

Author Information

Richard A. Detert, Ph.D., Professor Emeritus*

Health Education and Health Promotion

University of Wisconsin-La Crosse

424 N. 23rd Street, La Crosse, WI 54601

Ph.: 608-782-1538

E-Mail: detert.rich@uwlax.edu

Courtney Derosia, M.S.

211 West Allen Ridge Road

Springfield, MA 01118 
Ph.: 413-783-1052

E-Mail: cwheel@surfglobal.net

Tracy Caravella, Ph.D., Associate Professor Health Education and Health Promotion University of Wisconsin-La Crosse 200 Mitchell Hall, La Crosse, WI 54601

Ph.: 608-785-6788

E-Mail: caravell.trac@uwlax.edu

R. Daniel Duquette, Ed.D., Professor Health Education and Health Promotion University of Wisconsin-La Crosse

Ph.: 608-785-8161

E-Mail: duquette.rode@uwlax.edu

* corresponding author 